\title{
PEEP levels in COVID-19 pneumonia
}

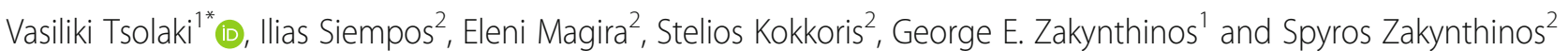

To the Editor:

Recently, the Surviving Sepsis Campaign COVID-19 guidelines and ATS suggest that a ventilatory strategy complying with the ARDSnet protocol should be applied to manage COVID-19 pneumonia [1-3]. However, "COVID-19 lung" pathophysiology seems to be divergent from the "ARDS lung"; hence, heart-lung interactions may be more pronounced than initially considered $[2,3]$.

We studied 17 patients (March 20-April 14, 2020) treated in two Greek University Intensive Care Units. Patients had COVID-19 pneumonia fulfilling the Berlin criteria of acute respiratory distress syndrome (ARDS) and were on the 2nd or 3rd day of invasive mechanical ventilation. Positive endexpiratory pressure (PEEP) was set according to predefined criteria [1-3]. Mean tidal volume ( \pm standard deviation) was $6.8 \pm 0.9 \mathrm{ml} / \mathrm{kg}$ ideal body weight $(469 \pm 64 \mathrm{ml})$, respiratory rate was $29.5 \pm 3.7$ breaths/min, and the fraction of inspired oxygen was $82 \pm 12 \%$. After measuring respiratory mechanics, arterial blood gases, and hemodynamics, we decreased PEEP by $25-30 \%$ (other mechanical ventilation variables remained stable). We re-evaluated measurements (1 h later) focusing on the effects of PEEP reduction on respiratory mechanics, hemodynamics, and fluid balance in a 12-h window before and after the PEEP change.

Mean PEEP reduction by $29 \%$ significantly increased respiratory system compliance and reduced hypercapnia, while oxygenation $\left(\mathrm{PaO}_{2} / \mathrm{FiO}_{2}\right)$ did not worsen (Table 1$)$. PEEP reduction was not accompanied by lung derecruitment, as oxygenation was not deteriorated. Rather PEEP reduction decreased lung overdistension as interpreted by the increase in respiratory system compliance and decrease in dead space ventilation (reduced $\mathrm{PaCO}_{2}$ ). Concerning hemodynamics, PEEP reduction was followed by a substantial decrease in noradrenaline dose,

\footnotetext{
* Correspondence: vasotsolaki@yahoo.com

${ }^{1}$ Intensive Care Unit, University Hospital of Larissa, Faculty of Medicine, University of Thessaly, Larissa, Greece

Full list of author information is available at the end of the article
}

most likely indicating improvement in cardiac output that allowed decrease in vasopressor dose, while blood pressure remained constant.

Application of unnecessary high PEEP (i.e., when PEEP does not result in lung recruitment) increases transpulmonary pressures, forcing West Zone 3 lung regions to Zones 2 and 1 . This phenomenon increases dead space ventilation, resulting in hypercapnia when minute ventilation remains constant. Pulmonary vascular resistance increases, leading to a variable degree of right ventricular dysfunction due to ventriculo-arterial uncoupling. PEEP effects may be exacerbated when the pulmonary vascular bed is injured, as in ARDS, where intravascular obstruction is observed due to thromboemboli [4]. A hypercoagulable state and extensive lung capillary thrombosis has also been reported in COVID-19 [5].

When lung compliance is relatively normal, substantial amount of the alveolar pressure is transmitted to the pleura. Therefore, relatively high PEEP in a nonrecruitable lung with almost normal compliance may significantly increase pleural pressure and have a detrimental impact on hemodynamics by deteriorating venous return. A conservative or de-resuscitative fluid strategy is recommended in the management of patients with ARDS [6]. Yet, in our patients, a strategy of increased PEEP approximating the ARDSnet protocol was accompanied by substantial vasopressor dosage and 12-h fluid balance. PEEP de-escalation led to significant reduction of cumulative fluid balance during the following $12 \mathrm{~h}$ and a three-fold decrease of vasopressor dosage. Decreased need for vasopressors and better fluid management translates in increased cardiac output and organ perfusion accompanied with less fluid accumulation in the lungs.

COVID-19 lung involvement is unique having a "pneumonia pattern" than being a typical "ARDS pattern" at least in the initial phase during the first days after intubation, and this was rather the case in our patient group [5]. Therefore, mechanical ventilation should 
Table 1 Respiratory and hemodynamic data in 17 mechanically ventilated patients with COVID-19, before and after PEEP reduction

\begin{tabular}{lllll}
\hline & Before & After & $\begin{array}{l}\text { Difference between before and after } \\
(95 \% \text { Cl) }\end{array}$ \\
\hline $\mathrm{PEEP}, \mathrm{cm} \mathrm{H})_{2} \mathrm{O}$ & $15.6 \pm 1.7$ & $11.1 \pm 1.9$ & $4.5(4.0$ to 5.0$)$ & $<$ value \\
$\mathrm{PaO}_{2} / \mathrm{FiO}_{2}, \mathrm{~mm} \mathrm{Hg}$ & $115.8 \pm 30.5$ & $121.9 \pm 26.3$ & $-6.1(-13.8$ to 1.6$)$ & 0.11 \\
$\mathrm{PaCO}_{2}, \mathrm{~mm} \mathrm{Hg}$ & $49.7 \pm 10.4$ & $42.9 \pm 5.6$ & $6.8(3.4$ to 10.1$)$ & 0.001 \\
$\mathrm{Cst}, \mathrm{ml} / \mathrm{cm} \mathrm{H} \mathrm{H}_{2} \mathrm{O}$ & $60.0 \pm 8.3$ & $63.2 \pm 7.4$ & $-3.2(-4.9$ to -1.5$)$ & 0.001 \\
Noradrenaline, $\mu \mathrm{g} / \mathrm{kg} / \mathrm{min}$ & $0.21 \pm 0.12$ & $0.08 \pm 0.08$ & $0.13(0.09$ to 0.16$)$ & $<0.001$ \\
MAP, $\mathrm{mm} \mathrm{Hg}$ & $67.2 \pm 6.1$ & $69.1 \pm 2.6$ & $-1.9(-4.4$ to 0.5$)$ & 0.11 \\
Fluid balance, $\mathrm{ml}$ & $1980 \pm 764^{\mathrm{b}}$ & $942 \pm 331^{\mathrm{c}}$ & $1039(760$ to 1317$)$ & $<0.001$ \\
\hline
\end{tabular}

Data are expressed as mean \pm standard deviation

${ }^{\mathrm{a}}$ Data are expressed as mean difference [95\% confidence interval $\left.(\mathrm{Cl})\right]$; ${ }^{\mathrm{b}}$ fluid balance during $12 \mathrm{~h}$ before PEEP reduction; ${ }^{\mathrm{C}}$ fluid balance during $12 \mathrm{~h}$ following PEEP reduction

PEEP positive end-expiratory pressure, $\mathrm{PaO}_{2}$ partial pressure of arterial oxygen, $\mathrm{FiO}_{2}$ fraction of inspired oxygen, $\mathrm{PaCO} \mathrm{C}_{2}$ partial pressure of arterial carbon dioxide, Cst static compliance of the respiratory system, MAP mean arterial pressure

be applied differently from the routinely followed ARDS protocol. Intensivists have to be cautious in discriminating between pneumonia and typical ARDS. Failure to discriminate between COVID-19 pneumonia and ARDS and adoption of erroneous ventilatory strategy may have detrimental effects on hemodynamics, resulting in organ hypoperfusion and ultimately multiorgan failure.

\section{Acknowledgements}

Not applicable.

\section{Authors' contributions}

Conceptualization: $\mathrm{SZ}, \mathrm{VT}, \mathrm{GZ}$, and IS. Acquisition, analysis, or interpretation of the data: $S Z, V T, G Z, I S, E M$, and SK. Statistical analysis: SZ and IS. Investigation: $S Z, G Z, S K, E M, G Z$, and VT. Drafting of the manuscript and editing: SZ, VT, GZ, and IS. Funding acquisition: not applicable. Supervision: SZ. All the authors involved read and approved the final manuscript.

\section{Funding}

None.

\section{Availability of data and materials}

Drs. Ilias Siempos, Eleni Magira, and Professor Spyros Zakynthinos had full access to all of the data in the study. After publication, the data will be made available to others on reasonable requests after approval from the corresponding author (VT, vasotsolaki@yahoo.com) and Evangelismos Hospital, Athens, and University Hospital of Larissa.

\section{Ethics approval and consent to participate}

Ethical approval was received by the Ethics Committee of the University Hospital of Larissa (2/4th/20/03/20 no 16963). Informed consent was waived by the Ethics Committee of both hospitals (Evangelismos and University Hospital of Larissa) as the procedures being performed were part of the routine care.

\section{Consent for publication}

The informed consents of patients were waived by the Ethics Commission of both hospitals (Evangelismos and University Hospital of Larissa) for the rapid emergence of this epidemic.

\section{Competing interests}

The authors declared no conflict of interest.

\section{Author details}

'Intensive Care Unit, University Hospital of Larissa, Faculty of Medicine, University of Thessaly, Larissa, Greece. ${ }^{2}$ Intensive Care Unit, Evangelismos General Hospital, National and Kapodistrian University of Athens Medical School, Athens, Greece.
Received: 21 May 2020 Accepted: 28 May 2020

Published online: 06 June 2020

\section{References}

1. Acute Respiratory Distress Syndrome Network, Brower R, Matthay M, Morris A, Schoenfeld D, Thompson T, Taylor B, Wheeler A. Ventilation with lower tidal volumes as compared with traditional tidal volumes for acute lung injury and the acute respiratory distress syndrome. N Engl J Med. 2000;342: 1301-8. https://doi.org/10.1056/NEJM200005043421801.

2. Alhazzani W, Møller M, Arabi Y, Loeb M, Gong MN, Fan E, Oczkowski S, Levy MM, Derde L, Dzierba A, Du B, Aboodi M, Wunsch H, Cecconi M, Koh Y, Chertow DS, Maitland K, Alshamsi F, Belley-Cote E, Greco M, Laundy M, Morgan JS, Kesecioglu J, McGeer A, Mermel L, Mammen MJ, Alexander PE, Arrington A, Centofanti JE, Citerio G, Baw B, Memish ZA, Hammond N, Hayden FG, Evans L, Rhodes A. Surviving sepsis campaign: guidelines on the management of critically ill. Intensive Care Med. 2020;46(5):854-87. https://doi.org/10.1007/s00134-020-06022-5.

3. Jamil S, Mark N, Carlos G, Dela Cruz C, Gross J, Pasnick S. Diagnosis and management of COVID-19 disease. Am J Resp Crit Care Med. 2020. https:// doi.org/10.1164/rccm.2020C1.

4. Zapol WM, Snider MT. Pulmonary hypertension in severe acute respiratory failure. N Engl J Med. 1977;296:476-80. https://doi.org/10.1056/ NEJM197703032960903.

5. Marini J, Gattinonni L. Management of COVID-19 respiratory distress. JAMA Published online April 24, 2020. doi:https://doi.org/10.1001/jama.2020.6825.

6. Silversides JA, Major E, Ferguson AJ, Mann E, McAuley D, Marshall J, Blackwood B, Fan E. Conservative fluid strategy or de-resuscitation for patients with sepsis or acute respiratory distress syndrome following the resuscitation phase of critical illness: a systematic review and meta-analysis. Intensive Care Med. 2017:43:155-70. https://doi.org/10.1007/s00134-0164573-3.

\section{Publisher's Note}

Springer Nature remains neutral with regard to jurisdictional claims in published maps and institutional affiliations.

\section{Ready to submit your research? Choose BMC and benefit from:}

- fast, convenient online submission

- thorough peer review by experienced researchers in your field

- rapid publication on acceptance

- support for research data, including large and complex data types

- gold Open Access which fosters wider collaboration and increased citations

- maximum visibility for your research: over $100 \mathrm{M}$ website views per year

At BMC, research is always in progress.

Learn more biomedcentral.com/submissions 